\title{
Evaluation of trace elements in equine piroplasmosis
}

\author{
LORA KOENHEMSI, FATMA ATEŞ ALKAN*, GIULIA MORGANTi**, \\ BORA Ü. BARUTÇU ${ }^{* * *}$, ERMAN M. OR
}

\begin{abstract}
Department of Internal Medicine, Faculty of Veterinary Medicine, Istanbul University-Cerrahpaşa, İstanbul, Turkey *Department of Biophysics, Faculty of Medicine, Beykent University, İstanbul, Turkey **Department of Veterinary Medicine of Perugia, Perugia, Italy

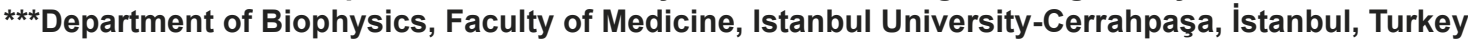

\section{Koenhemsi L., Ateş Alkan F., Morganti G., Barutçu B. Ü., Or E. M. Evaluation of trace elements in equine piroplasmosis}

\section{Summary}

Equine piroplasmosis (EP) is a tick-borne disease caused by Babesia caballi and Theileria equi, which causes a significant economic loss. The aim of this study was to determine the disease-related changes of serum trace elements that play an important role in the immune system. Our study was conducted on 20 horses with piroplasmosis and $\mathbf{2 0}$ healthy horses. It was performed to evaluate some of the serum trace element levels (chromium $(\mathrm{Cr})$, copper $(\mathrm{Cu})$, iron $(\mathrm{Fe})$, magnesium $(\mathrm{Mg})$ manganese $(\mathrm{Mn})$, selenium $(\mathrm{Se})$, zinc $(\mathrm{Zn})$, arsenic (As), boron (B), and nickel (Ni)) in equine piroplasmosis. The elements were analyzed in serum using ICP-OES. Infected horses had significantly higher serum Mg and Mn levels. In conclusion, changes of serum trace elements in infected horses can provide valuable information about pathophysiological aspects and they are also good indicators for diagnosis, prognosis and treatment evaluation. Much more scientific research is required to evaluate the trace elements related to equine piroplasmosis.

Keywords: Babesia caballi, Theileria equi, horse, equine piroplasmosis, serum trace elements

Equine piroplasmosis (EP) is a tick-borne disease of all wild and domestic equids caused by the intraerythrocytic protozoan parasites Babesia caballi and Theileria equi (formerly Babesia equi), which may be observed separately or together $(2,13,15)$. Since it has harmful effects on the health and thus the performance of equids, EP is considered as a serious threat. Clinical presentation of piroplasmosis is related to erythrocyte lysis that causes intravascular hemolysis and associated systemic illnesses $(13,16)$. The disease is characterized by jaundice, anemia, edema, red urine, hemoglobinuria, weight loss, and sometimes death. EP is known to be manifested in three stages: acute, latent, and subclinical. Horses infected with Theileria equi have more severe clinical signs than those with Babesia caballi (2). The disease can be diagnosed by indirect immunefluorescent antibody test (IFAT), enzyme-linked immunoassays (ELISA), and polymerase chain reaction (PCR), as well as Giemsa-stained blood smears $(2,7)$.

Even though the tick vector, parasite host requirements for infection or clinical disease are not fully understood to this day, the clinical data suggest that the decreased immunological reactions of horses and the increased density of infected ticks are also important in the formation of the disease $(4,16)$. There is increasing evidence showing that trace elements may be critical for maintaining the animal's immune system (8). In addition, recent studies suggest that altered levels of trace elements might be associated with the anti-parasitic immune response (2).

The possible association between the parasitic infection and the occurrence of changes in trace elements may play a fundamental role in the progression, the estimation of prognosis, and the treatment of EP. The present study has been conducted to determine if there is any alteration of serum trace elements in Equine piroplasmosis in order to achieve a more comprehensive view of the disease.

\section{Material and methods}

Overall 40 horses, ranging from 3 to 7 years of age, were selected in a EP-endemic area of Central Italy (Umbria region). The animals originated from n. 4 farms and were maintained on similar diets that were adequate and balanced to their requirements. De-worming was regularly administrated. Twenty animals tested serologically positive by Indirect Immunofluorescence Antibody test (IFAT) both for $B$. caballi and $T$. equi and presented symptoms associated to EP during clinical examination (i.e. fever, jaundice, anemia, sportive performance loss). The remaining 20 horses were in good general health, did not present IgG antibodies against $B$. caballi and T. equi in their serum 
samples and served as a control group. All animals were also tested for other Tick-borne pathogens (TBPs) (i.e. Borrelia bourgdorferi, Anaplasma phagocytophilum) always detected in the study area.

The IFAT test was performed using commercial antigens (MegaScreen ${ }^{\circledR}$ FLUOBABESIA caballi/MegaScreen ${ }^{\mathbb{B}}$ FLUOTHEILERIA equi/MegaScreen ${ }^{\circledR}$ FLUOANAPLASMA ph/MegaScreen ${ }^{\circledR}$ FLUOBORRELIA) obtained from DIAGNOSTIK MEGACORE Laboratories (Horbranz, Austria) and a fluorescein-conjugated anti-horse antibodies (rabbit-anti Horse-IgG-FITC, Sigma Immunochemicals, St. Louis, MO, USA), diluted 1/200 in Blue Evans solution. All samples were screened at an initial dilution of $1 / 80$ in a phosphate-buffered saline solution $(\mathrm{pH} \mathrm{7.2)} \mathrm{and}$ then diluted in order to determine the end-point titer. Horse serum samples were used as negative and positive controls.

The blood samples were centrifuged for 20 minutes, and serum samples were centrifuged at $4000 \mathrm{rpm}$ for $15 \mathrm{~min}$ utes in a Hettich Universal centrifuge. The serum samples obtained were stored at $-80^{\circ} \mathrm{C}$ until the analysis of trace elements. They were prepared for trace element analyses by diluting $1: 20$ with deionized water. The analyses of trace elements were performed with an inductively coupled plasma-optical emission spectrophotometer (ICP-OES Thermo iCAP 6000 series). Each analysis was applied twice, and the acquired averages were used. Serum results were expressed as micrograms per milliliter $[\mathrm{ppm}=\mu \mathrm{g} / \mathrm{mL}]$. The
Tab. 1. Table of used wavelengths $(\mathrm{nm})$ for all analyzed trace elements

\begin{tabular}{|l|c|}
\hline Trace elements & Wavelengths \\
\hline $\mathrm{Cr}$ & 267.716 \\
$\mathrm{Cu}$ & 327.396 \\
$\mathrm{Fe}$ & 259.940 \\
$\mathrm{Mg}$ & 285.213 \\
$\mathrm{Mn}$ & 257.610 \\
$\mathrm{Se}$ & 196.090 \\
$\mathrm{Zn}$ & 206.200 \\
$\mathrm{As}$ & 189.040 \\
$\mathrm{~B}$ & 249.773 \\
$\mathrm{Ni}$ & 221.647 \\
\hline
\end{tabular}
appropriate wavelengths, that is, $267.716 \mathrm{~nm}, 327.396 \mathrm{~nm}$, $259.940 \mathrm{~nm}, 285.213 \mathrm{~nm}$, $257.610 \mathrm{~nm}, 196.090 \mathrm{~nm}$, $206.200 \mathrm{~nm}, 189.040 \mathrm{~nm}$, $249.773 \mathrm{~nm}, 221.647 \mathrm{~nm}$, and $251.611 \mathrm{~nm}$, were used to determine the levels of chromium $(\mathrm{Cr})$, copper $(\mathrm{Cu})$, iron $(\mathrm{Fe})$, magnesium (Mg) manganese $(\mathrm{Mn})$, selenium $(\mathrm{Se})$, zinc ( $\mathrm{Zn})$, arsenic (As), boron (B), and nickel (Ni), respectively (Tab. 1). In ICP-OES, the plasma operating conditions were as follows: 15

\section{Results and discussion}

Results concerning B. caballi and T. equi IFAT tests in infected horses group are given in Table 2. No antibodies of other TBPs were detected in both groups. Infected horses had significantly higher serum $\mathrm{Mg}$ and $\mathrm{Mn}$ levels than healthy animals $(\mathrm{p}<0.001)($ Tab. 3).

Piroplasmosis is a globally significant disease which is considered endemic in a majority of countries worldwide. Despite the fact that the immune system is one of the most crucial predisposing factors in the development of the disease, only limited information is known about the immune response (16). Moreover, although the trace elements play a significant role in the immune system

Tab. 2. The IFAT of the horses

\begin{tabular}{|c|c|c|}
\hline No & Babesia caballi IgG & Theileria equi IgG \\
\hline 1 & $1 / 320$ & $>1 / 640$ \\
\hline 2 & $1 / 640$ & $1 / 160$ \\
\hline 3 & $1 / 160$ & $1 / 1280$ \\
\hline 4 & $1 / 1280$ & $1 / 1280$ \\
\hline 5 & $1 / 640$ & $1 / 320$ \\
\hline 6 & $1 / 80$ & $1 / 640$ \\
\hline 7 & $1 / 80$ & $1 / 640$ \\
\hline 8 & $1 / 320$ & $1 / 320$ \\
\hline 9 & $1 / 320$ & $1 / 640$ \\
\hline 10 & $1 / 320$ & $1 / 80$ \\
\hline 11 & $1 / 640$ & $1 / 320$ \\
\hline 12 & $1 / 320$ & $1 / 640$ \\
\hline 13 & $1 / 640$ & $1 / 1280$ \\
\hline 14 & $1 / 320$ & $1 / 640$ \\
\hline 15 & $1 / 160$ & $1 / 320$ \\
\hline 16 & $1 / 160$ & $1 / 640$ \\
\hline 17 & $1 / 320$ & $1 / 640$ \\
\hline 18 & $1 / 640$ & $>1 / 1280$ \\
\hline 19 & $1 / 1280$ & $1 / 640$ \\
\hline 20 & $1 / 640$ & $1 / 320$ \\
\hline
\end{tabular}

$\mathrm{L} / \mathrm{min}$ plasma gas flow rate; 0.5 argon car- rier flow rate; $1.51 \mathrm{~L} / \mathrm{min}$ sample and elution flow rate. The peristaltic pump speed was set at $100 \mathrm{rpm}$. The transport lines were made of PTFE (polytetrafluoroethylene) tubes of $1.25 \mathrm{~mm}$ internal diameter (1).

For all data, statistical analysis was performed by SPSS 21, the statistical software for Windows. Variables were performed with the One Way Anova parametric test in order to determine the statistical comparison of the groups. Means were presented with standard deviations (SD). The mean and median values were represented along with their $95 \%$ confidence intervals. All the analyses were considered statistically significant at $\mathrm{p}<0.001$.

Tab. 3. Trace element levels in healthy horses and horses with piroplasmosis $(\overline{\mathbf{x}} \pm \mathrm{SD})$

\begin{tabular}{|l|c|c|c|c|c|c|}
\hline \multirow{2}{*}{ Elements } & \multicolumn{2}{|c|}{ Patient $(\mathrm{n}=20)$} & \multicolumn{2}{c|}{ Healthy $(\mathrm{n}=20)$} & \multirow{2}{*}{ SEM } & \multirow{2}{*}{ P Value } \\
& Mean & SD & Mean & SD & & \\
\hline $\mathrm{Cr}(\mu \mathrm{g} / \mathrm{ml})$ & 0.003 & 0.001 & 0.004 & 0.003 & 0.001 & $0.435-\mathrm{NS}$ \\
$\mathrm{Cu}(\mu \mathrm{g} / \mathrm{ml})$ & 0.600 & 0.200 & 0.549 & 0.182 & 0.040 & $0.667-\mathrm{NS}$ \\
$\mathrm{Fe}(\mu \mathrm{g} / \mathrm{ml})$ & 1.500 & 0.700 & 1.631 & 0.898 & 0.200 & $0.210-\mathrm{NS}$ \\
$\mathrm{Mg}(\mu \mathrm{g} / \mathrm{ml})$ & 10.81 & 5.17 & 8.625 & 4.315 & 0.300 & $<0.001^{*}$ \\
\hline $\mathrm{Mn}(\mu \mathrm{g} / \mathrm{ml})$ & 0.0005 & 0.0009 & 0.0003 & 0.001 & & $<0.001^{*}$ \\
$\mathrm{Se}(\mu \mathrm{g} / \mathrm{ml})$ & 0.213 & 0.072 & 0.200 & 0.060 & & $0.425-\mathrm{NS}$ \\
\hline $\mathrm{Zn}(\mu \mathrm{g} / \mathrm{ml})$ & 0.32 & 0.12 & 0.339 & 0.187 & & $0.793-\mathrm{NS}$ \\
\hline As $(\mu \mathrm{g} / \mathrm{ml})$ & 0.458 & 0.139 & 0.493 & 0.143 & & $0.270-\mathrm{NS}$ \\
\hline $\mathrm{B}(\mu \mathrm{g} / \mathrm{ml})$ & 0.110 & 0.040 & 0.090 & 0.040 & & $0.722-\mathrm{NS}$ \\
$\mathrm{Ni}(\mu \mathrm{g} / \mathrm{ml})$ & 0.033 & 0.032 & 0.030 & 0.030 & & $0.600-\mathrm{NS}$ \\
\hline
\end{tabular}

Explanation: $* \mathrm{p}<0.001$ 
only a few studies have been done regarding some of the serum trace elements infected with EP $(2,17)$.

In a study of Knowles et al. (4), it was concluded that specific immune responses were required to control EP. Recent studies have also suggested that trace elements participated in the activation of immune cells. The deficiency of trace elements is vital since it can increase the risk of morbidity and mortality (2).

Copper $(\mathrm{Cu})$ has both antiparasitic activity and a positive effect on the immunity of hosts (6). In addition, this element is essential for hemoglobin production since $\mathrm{Cu}$ deficiency leads to anemia. Thus, increased levels of $\mathrm{Cu}$ may be detected in inflammatory diseases and anemia $(2,5) . \mathrm{Cu}$ is a prominent part of the acute phase protein, ceruloplasmin. Depending on the increase in ceruloplasmin levels during inflammatory conditions, $\mathrm{Cu}$ levels rise in the blood (2). Although similar to the study conducted by Dede et al. (2), Zaeemi et al. (17) found lower levels of serum $\mathrm{Cu}$ in horses with theileriosis, there was no statistically significant alteration in the serum $\mathrm{Cu}$ levels in our study. This finding is also similar to another study in ovine theileriosis (9).

As for the association of iron $(\mathrm{Fe})$ with infections, research has been ongoing for a considerable period of time. High levels of Fe can be detected in EP cases due to extravascular hemolytic anemia. In acute stages of the disease, decreased Fe levels have been reported because of the altered erythrocytic metabolism $(14,18)$. Moreover, Zaeemi et al. (17) determined that serum Fe levels were analyzed within the limits in horses and donkeys with piroplasmosis in accordance with our study.

Another essential macroelement that has a role in protection against neurotoxicity, cardiotoxicity, inflammation, and free radical damage is magnesium $(\mathrm{Mg})$. Hypomagnesemia is associated with critically ill patients in intensive care units. In addition, lower $\mathrm{Mg}$ levels are also associated with gastrointestinal and infectious respiratory diseases as well as multiorgan diseases (12).

According to studies (5) manganese (Mn) levels are induced by IL- 1 and TNF- $\alpha$. Nazifi et al. (9) detected increased levels of Mn on ovine theileriosis. However, in another study, low levels of Mn were found in cattle with theileriosis (11). In our study, an increase in Mn levels was observed in the EP group when compared.

As is widely known, in high concentrations selenium (Se) is a toxic trace element but lower levels are required for animal health (8). Low levels of Se in cattle with theileria was detected in the study of Razavi et al. (11). In this study, there was no significance found in Se levels among the EP and the healthy control group.

Zinc $(\mathrm{Zn})$ has a role in the immune function regulation such as cytokine secretion and T cell damage (6). Lower $\mathrm{Zn}$ levels can be observed in anemia, hormonal changes, increased demand of the parasite, and the indirect effect of the parasite host relationship (2). $\mathrm{Zn}$ is also vital in macrophage uptake and killing of the parasite (14). In cases of piroplasmosis during the release of merozoites, rupture of the erythrocytes comprise intravascular hemolytic anemia (16). However, in our study Zn levels were within the normal range, and there was no statistical difference between EP and healthy animals.

Chromium $(\mathrm{Cr})$, arsenic (As) and nickel $(\mathrm{Ni})$ are ultra-trace elements and presumed essential for ruminants. Nevertheless, research data are not available about equines and diseases. The levels of $\mathrm{Cr}$, As and $\mathrm{Ni}$ revealed no significance in our study.

Boron (B) is an essential trace element that the detailed mechanism of B functions in animals has not yet been fully elucidated. Since it is one of the important trace elements for bone growth and health (3), its role in mineral metabolism, in immune response, and in the endocrine system cannot be overlooked. In our study, there were no differences between EP and healthy groups.

In conclusion, the detection of these changes of trace elements suggests a possible long-term health impact on infected equids. Further scientific study is required to substantiate the role of trace elements in the immunological response of the diseases.

\section{References}

1. Alkan Ates F., Karis D., Cakmak G., Ercan A. M.: Analysis of the relationship between hemorheologic parameters, aluminum, manganese, and selenium in smokers. Biol. Trace Elem. Res. 2018, 1-10, doi: 10.1007/s12011-018-1352-8.

2. Dede S., Değer Y., Değer S., Tanritanır P.: Plasma levels of zinc, copper, coper/ zinc ratio and activity of carbonic anyhdrase in eqine piroplasmosis. Biol. Trace Elem. Res. 2008, 125, 41-45, doi: 10.1007/s12011-008-8136-5.

3. Kabu M., Akosman M. S.: Biological effects of boron. Rev. Environ. Contam. Toxicol. 2013, 225, 57-75.

4. Knowles D. P., Kappmeyer L. S., Perryman L. E.: Specific immun responses are required to control parasitemia in Babesia equi infection. Infect. Immun. 1994 62, 1909-1913

5. Koçyiğit A., Erel O., Gürel M. S., Avcı S., Aktepe N.: Serum selenium, zinc, copper and iron concentrations and some related antioxidant enzymes in patients with cutaneous leishmaniasis. Biol. Trace Elem. Res. 1998, 65, 271-281.

6. Koski K. G., Scott M. E.: Gastrointestinal nematodes, trace elements, and immunity. J. Trace Elem. Exp. Med. 2003, 16, 237-251.

7. Mahmoud M. S., Abu El-Ezz N. T., Abdel-Shafy S., Nassar S. A., El Namaky A. H., Khalil W. K. B., Knowles D. P., Kappmeyer L. S., Silva M. G., Suarez C. E.: Assessment of Theleria equi and Babesia caballi infections in equine populations in Egypt by molecular, serological and hematological approaches. Parasit. Vectors 2016, 9, 260-270, doi: 10.1186/s13071-016-1539-9.

8. Mayland H. F., Glenn E., Shewmaker E.: Animal health problms caused by silicon and other mineral imbalances. J. Range Manage. 2001, 54, 441-446.

9. Nazifi S., Razavi S. M., Safi N., Rakhshandehroo E.: Malignant ovine theileriosis: alterations in the levels of homocysteine, thyroid hormones and serum trace elements. J. Bacteriol. Parasitol. 2012, 3, 1-4, doi: 10.4172/2155-9597.1000150.

10. OIE Terrestrial Manuel.: Equine piroplasmosis. http://www.oie.int/fileadmin Home/fr/Health_standards/tahm/2.05.08_equine_piroplasmosis.pdf 2014 .

11. Razavi S. M., Nazifi S., Bateni M., Rakhshandehroo E.: Alterations of erythrocyte antioxidant mechanisms: Antioxidant enzymes, lipid peroxidation and serum trace elements associated with anemia in bovine tropical theileriosis. Vet. Parasitol. 2011, 180, 209-214, doi: 10.1016/j.vetpar.2011.03.011.

12. Stewart A. J.: Magnesium disorders in horses. Vet. Clin. North Am. Equine Pract. 2011, 27, 149-163, doi: 10.1016/j.cveq.2010.12.009.

13. Veronesi F., Morganti G., Ravagnan S., Laus F., Spaterna A., Diaferia M., Moretti A., Fioretti D. P., Capelli G.: Molecular and serological detection of tick-borne pathogens in donkeys (Equus asinus) in Italy. Vet. Microbio. 2014, 173, 348-354.

14. Wirth J. J., Fraker P. J., Kierszenbaum F.: Zinc requirement for macrophage function: effect of zinc deficiency on uptake and killing of protozoan parasite. Immunology 1989, 68, 114-119.

15. Wise L. N., Kappmeyer L. S., Mealey R. H., Knowles D. P.: Review of equine piroplasmosis. J. Vet. Intern. Med. 2013, 27, 1334-1346, doi: 10.1111/jvim.12168.

16. Wise L. N., Pelzel-McCluskey A. M., Mealey R. H., Knowles D. P.: Equine piroplasmosis. Vet. Clin. North Am. Equine Pract. 2014, 30, 673-693, doi: 10.1016/ j.cveq.2014.08.008

17. Zaeemi M., Razmi G. R., Mohammadı G. R., Abedi V., Yaghfoori S.: Evaluation of serum biochemical profile in Turkoman horses and donkeys infected with Theileria equi. Rev. Med. Vet. 2016, 167, 301-309.

18. Zobba R., Ardu M., Niccolini S., Chessa B., Manna L., Cocco R., Parpaglia M. L. P.: Clinical and laboratory findings in equine piroplasmosis. J. Equine Vet. Sci. 2008, 28, 301-308, doi: 10.1016/j.jevs.2008.03.005.

Corresponding author: Lora Koenhemsi, DVM, PhD, Istanbul University, Faculty of Veterinary Medicine, Department of Internal Medicine, AvcilarIstanbul, Turkey 34320; e-mail: lomekoh@istanbul.edu.tr 